\title{
Yu.Yu.Sapicheva, V.L.Kassil, I.Kh.Khapiy \\ Alveolar recruitment for treatment of hypoxemia in acute respiratory failure
}

\begin{abstract}
Summary
The objective of this study was to select the optimal method of alveolar recruitment in patients with refractory hypoxemia. We used the APACHE II scale to assess the severity of the patient's status. We also investigated effects of alveolar recruitment on the blood gas exchange, the central haemodynamics and liquid balance in patients with acute respiratory failure. Patients involved in the study $(n=100)$ were divided into 3 groups. The control group $(n=45)$ was treated with conventional mechanical ventilation. A group with moderate hypoxemia $(n=32)$ was treated using a "sparing" alveolar recruitment technique with noninvasive monitoring of the arterial pressure, the heart beat rate, and $\mathrm{SpO}_{2}$. A group with severe hypoxemia $(n=23)$ was treated using an "aggressive" alveolar recruitment technique with noninvasive monitoring of the arterial pressure, the heart beat rate and $\mathrm{SpO}_{2}$, blood gases analysis, monitoring of the central haemodynamics, measurements of cardiac output (CO), cardiac index (CI), intrathoracic blood volume index (ITBVI), global end-diastolic volume index (GEDVI), extravascular lung water index (ELWI), and systemic vascular resistance (SVR) by the PICCO monitor. Both methods of alveolar recruitment significantly increased arterial oxygenation but did not worsen the haemodynamics. After the procedure, tidal volume and dynamic lung compliance increased. Alveolar recruitment did not influence on ELWI but decreased peak ITBVI and peak GEDVI. After the procedure of alveolar recruitment, these parameters returned to the baseline. Therefore, alveolar recruitment could improve arterial blood oxygenation and increase number of ventilated alveoli without any negative effects on haemodynamics.

Key words: alveolar recruitment, ventilation, arterial hypoxemia, pneumonia, sepsis.
\end{abstract}

\section{Резюме}

Целью исследования был выбор оптимальных методик приема мобилизации альвеол при стойкой гипоксемии в зависимости от степени тяжести состояния больных и изучение их влияния на газообмен и центральную гемодинамику при паренхиматозной острой дыхательной недостаточности $(\mathrm{OДН)}$. Пациенты $(n=100)$ были разделены на 3 группы. Пациентам контрольной группы $(n=45)$ проводилась общепринятая искусственная вентиляция легких (ИВЛ). В группе больных с умеренной гипоксемией $(n=32)$ осуществлялась мобилизация альвеол по "щадящей" методике (измерялись неинвазивно артериальное давление (АД), частота сердечных сокращений (ЧСС), насыщение артериальной крови кислородом $\left.-\mathrm{SpO}_{2}\right)$. В группе пациентов с выраженной гипоксемией $(n=23)$ мобилизация альвеол проводилась по "агрессивной" методике (мониторировались АД, ЧСС, $\mathrm{SpO}_{2}$, измерялись газы крови, сердечный выброс и индекс, индекс внутригрудного объема крови (ИВГОК), индекс внесосудистой воды легких (ИВСВЛ), индекс глобального конечно-диастолического объема (ИГКДО), системное сосудистое сопротивление монитором РіССО. Мобилизация альвеол по обеим методикам значительно повышала оксигенацию артериальной крови, но не оказывала выраженного отрицательного действия на гемодинамику. Увеличивались дыхательный объем, динамический комплаенс легких, $\mathrm{SpO}_{2}$. Мобилизация альвеол не оказывала воздействия на ИВСВЛ, но на его высоте отмечено снижение ИГКДО и ИВГОК. После мобилизации показатели вернулись к прежним параметрам.

Таким образом, мобилизации альвеол улучшает артериальную оксигенацию, увеличивает количество вентилируемых альвеол, не оказывает выраженного отрицательного действия на гемодинамику.

Ключевые слова: мобилизация альвеол, искусственная вентиляция легких, артериальная гипоксемия, пневмония, сепсис.

Практически любая дыхательная недостаточность всегда приводит к развитию гипоксемии - снижению напряжения кислорода в артериальной крови $\left(\mathrm{PaO}_{2}\right)$ и насыщения ее кислородом $\left(\mathrm{SpO}_{2}\right)$. Особенно это относится к острой дыхательной недостаточности (ОДН), при которой гипоксемия часто является основной непосредственной причиной смерти больного

Выделяют вентиляционную ОДН, когда страдает аппарат, обеспечивающий сам акт внешнего дыхания (центральная регуляция дыхания, работа дыхательных мышц, например диафрагмы, стабильность реберного каркаса), и паренхиматозную ОДН, при которой ухудшается газообменная функция легких (обширная пневмония, острый респираторный дистресс-синдром (ОРДС), отек легких и др.).
Особенно выраженная и трудноустранимая гипоксемия возникает при ОРДС, который классифицируют на легочный и внелегочный. Легочным называют ОРДС, развивающийся при терминальных стадиях различных первичных острых поражений легких - аспирационном пневмоните, бактериальных и вирусных пневмониях, утоплении, ингаляции токсических веществ и ушибах легких когда индекс оксигенации $\left(\mathrm{PaO}_{2} / \mathrm{FiO}_{2}\right)$ снижается до значения $<200[1,2]$. Внелегочный ОРДС развивается как неспецифическая реакция первоначально неповрежденных легких на длительные расстройства периферической микроциркуляции с гипоперфузией тканей и возникновением тяжелой и длительной циркуляторной гипоксии [3]. При начальных стадиях внелегочного ОРДС $\mathrm{PaO}_{2} / \mathrm{FiO}_{2}$ может быть и су- 
щественно выше 200, но гипоксемия нарастает и становится резистентной к повышению фракции кислорода во вдыхаемом газе $\left(\mathrm{FiO}_{2}\right)$. Более всего на развитие гипоксемии при паренхиматозной дыхательной недостаточности, в частности при ОРДС, а также пневмонии влияют коллабирование альвеол (возникновение множественных необтурационных микроателектазов) и интерстициальный (некардиогенный) отек легких.

Искусственная вентиляция легких (ИВЛ) - эффективный метод улучшения оксигенации артериальной крови у больных с паренхиматозной дыхательной недостаточностью, но при тяжелых формах этой патологии традиционные методы ИВЛ со снижением давления во время выдоха до нуля часто оказываются неэффективными и требуют создания положительного давления в конце выдоха (ПДКВ), которое способствует росту артериальной оксигенации [4]. Однако ПДКВ само по себе не способно раскрыть все спавшиеся альвеолы.

В последнее время одним из способов устранения резистентной гипоксемии является метод мобилизации альвеол, направленный на то, чтобы открыть альвеолы и удержать их в этом состоянии $[5,6]$. Эффективность данного приема очень высока, в особенности на ранних стадиях ОРДС [4, 7-11]. Также показано, что повторная мобилизация альвеол сопровождается снижением частоты развития т. н. респиратор-ассоциированных повреждений легких [12]. Однако существует мнение, что метод мобилизации альвеол опасен в связи со значительным увеличением внутрилегочного давления, что может привести к выраженному нарушению центральной гемодинамики и будет сопровождаться повреждением легких вплоть до пневмоторакса. Кроме того, процедура может вызвать перераздувание непораженных альвеол [13] и повредить их [14].

Целью данного исследования явился выбор оптимальных методик приема мобилизации альвеол при гипоксемии, резистентной к другим методам лечения в зависимости от степени тяжести ОДН. Кроме того, необходимо было изучить их влияние на газы крови, центральную гемодинамику и жидкостной баланс легких у больных с острой паренхиматозной дыхательной недостаточностью.

\section{Материалы и методы}

В исследовании участвовали 100 больных (54 мужчины и 46 женщин) с ОДН различной этологии. По тяжести состояния (согласно шкале АРАCHE-II) всех пациентов разделили на 3 группы. Патологические процессы, вызвавшие ОДН у обследуемых больных, представлены в табл. 1 .

В 1-ю группу (ретроспективный анализ) вошли 45 пациентов. У 12 из них ОДН развилась в результате 2-сторонней пневмонии. 25 больных были доставлены с признаками гипоксемии после полостных операций. У них ОДН была связана с появлением компрессионных ателектазов, а также с использованием искусственного кровообращения (10 пациентов). 20 больным проводили длительную ИВЛ в различных учреждениях; они были переведены в отделение реанимации МОНИКИ (Москва) из-за прогрессируюшего ухудшения состояния. Во 2-ю группу вошли больные, перенесшие хирургические вмешательства. При этом 26 человек поступили сразу же после полостных операций. Причиной гипоксемии у них были компрессионные ателектазы, 6 пациентам применяли искусственное кровообращение. Еще у 6 больных после операций на органах брюшной полости на 4-6-е сут. развилась ОДН, вызванная пневмонией. У 14 пациентов 3-й группы развился ОРДС на фоне септических осложнений основного заболевания. У 9 пациентов проводились аорто-коронарное шунтирование и протезирование клапанов (у 5 из них применяли искусственное кровообращение), у них развился внелегочный ОРДС ранних стадий.

По тяжести состояния и степени гипоксемии 1-я и 2-я группа не различались (табл. 2). У пациентов 1-й группы для достижения приемлемой оксигенации крови $\left(\mathrm{SpO}_{2}>90 \%\right)$ проводили ИВЛ с высокой фракцией вдыхаемого кислорода $\left(\mathrm{FiO}_{2}\right)$, превышающей общепринятый уровень безопасности $(>0,6)$. Такое высокое $\mathrm{FiO}_{2}$ приходилось поддерживать на протяжении 4-12 ч. У 6 пациентов снизить $\mathrm{FiO}_{2}$ вообще не удалось. У этих больных мобилизацию альвеол не проводили, т. к. данный прием пока не внедрен в клиническую практику. Летальность в этой группе составила $13 \%$.

У больных 2-й группы прием мобилизации альвеол проводили по "щадящей" методике. Здесь критерием включения в исследование являлось снижение $\mathrm{SpO}_{2}<90 \%$. Умерших больных не было.

В 3-ю группу вошли 23 пациента с ОРДС и тяжелой, плохо поддающей устранению гипоксемией $\left(\mathrm{SpO}_{2}<90 \%\right.$, не повышающееся при $\left.\mathrm{FiO}_{2}>0,65\right)$. Этим больным проводили прием мобилизации альвеол по "агрессивной" методике. Как видно из табл. 2, состояние больных 3-й группы было значительно более тяжелым, чем в 1-й и 2-й группе: более высокий индекс по шкале АРАСНЕ-II, нестабильное

Таблица 1

Основные причины развития ОДН

\begin{tabular}{|c|c|c|c|}
\hline Причины ОДН & $\begin{array}{c}1 \text {-я группа } \\
(n=45)\end{array}$ & $\begin{array}{c}2 \text {-я группа } \\
(n=32)\end{array}$ & $\begin{array}{c}\text { 3-я группа } \\
(n=23)\end{array}$ \\
\hline Пневмония & 12 & 6 & \\
\hline Сепсис, ОРДС (2-сторонняя пневмония, медиастинит, панкреонекроз, перитонит) & 8 & & 14 \\
\hline Множественные компрессионные ателектазы после операций на органах грудной и брюшной полостей & 15 & 20 & 4 \\
\hline Длительная экстракорпоральная перфузия при операциях на сердце, ОРДС & 10 & 6 & 5 \\
\hline
\end{tabular}

http://www.pulmonology.ru 
Таблица 2

Общая характеристика больных при поступлении в отделение реанимации и интенсивной терапии

\begin{tabular}{|c|c|c|c|}
\hline Показатели & 1-я группа & 2-я группа & 3-я группа \\
\hline Число больных & 45 & 32 & 23 \\
\hline Возраст, годы & $56,0 \pm 2,5$ & $54,6 \pm 2,6$ & $53,2 \pm 2,5$ \\
\hline $\begin{array}{l}\text { Тяжесть состояния по } \\
\text { шкале АРАCHE-II, баллы }\end{array}$ & $9,0 \pm 2,0$ & $11,0 \pm 2,0$ & $20,0 \pm 1,5^{*}$ \\
\hline $\begin{array}{l}\text { Число больных, которые } \\
\text { нуждались в инотропной } \\
\text { поддержке, } n(\%)\end{array}$ & $10(21,7)$ & $9(28,1)$ & $10\left(71,4^{*}\right)$ \\
\hline $\begin{array}{l}\text { АД систолическое, } \\
\text { мм рт. ст. }\end{array}$ & $140,0 \pm 3,8$ & $150,2 \pm 20,7$ & $107,5 \pm 9,2^{*}$ \\
\hline $\begin{array}{l}\text { АД диастолическое, } \\
\text { мм рт. ст. }\end{array}$ & $70,0 \pm 2,2$ & $75,0 \pm 1,8$ & $63,0 \pm 2,8$ \\
\hline ЧСС, мин ${ }^{-1}$ & $110,0 \pm 2,9$ & $98,8 \pm 2,6$ & $98,0 \pm 2,2$ \\
\hline $\mathrm{SpO}_{2}, \%$ & $90,00 \pm 0,45$ & $90,5 \pm 0,7$ & $93,4 \pm 0,1$ \\
\hline $\mathrm{FiO}_{2}$ & $0,80 \pm 0,02$ & $0,61 \pm 0,02$ & $0,55 \pm 0,07$ \\
\hline ПДКВ, см вод. ст. & $7,3 \pm 1,8$ & 5,0 & $7,0 \pm 1,0$ \\
\hline
\end{tabular}

Примечание: ПДКВ - положительное давление в конце выдоха; * - $p<0,05$ по сравнению с 1-й и 2-й группой.

артериальное давление, более частая необходимость в применении кардиотоников. Критерием включения в исследования пациентов 3-й группы являлось падение $\mathrm{PaO}_{2} / \mathrm{FiO}_{2}<200$.

Всем пациентам проводили мониторинг артериального давления (АД), частоты сердечных сокращений (ЧСС), электрокардиографию (ЭКГ) и пульсоксиметрию на мониторах Nihon Kohden BSM-2301 (Nihon Kohden corp, Япония). У больных II и III групп исследовали газы и KOC крови на анализаторе ABL 800 FLEX фирмы Radiometer Copenhagen (Дания). Кроме того, у 14 больных 3-й группы осуществляли инвазивный мониторинг центральной гемодинамики и жидкостного баланса легких методом препульмональной термодилюции при помощи монитора PiCCO (Pulsion Medical Systems, Германия). Артериальный катетер вводили в бедренную артерию для измерения сердечного выброса (СВ), сердечного индекса (СИ), индекса внутригрудного объема крови (ИВГОК), индекса глобального конечнодиастолического объема (ИГКДО), системного сосудистого сопротивления (ССС). Измерения проводили сразу после установки катетера, до приема мобилизации, на пике приема и сразу после мобилизации.

Для респираторной поддержки во всех группах больных использовали респираторы LTV 1000 (Pulmonatic systems, США), NBP-760 и NBP-840 (Nellcor Puritan Bennett, Ирландия) и Neumovent (TECME S.A., Аргентина).

\section{Методика мобилизации альвеол}

Использовали 2 методики. В соответствии с 1-й из них респиратор, которым осуществляли объемную ИВЛ с ПДКВ 7-8 см вод. ст., переводили в режим постоянно положительного давления в дыхательных путях (ППД, или СРАР), причем давление поддерживали на уровне 20 см вод. ст. в течение 30 с ("20 × 30”). Затем возобновляли ИВЛ в прежнем режиме, но устанавливали ПДКВ на 2 см вод. ст. выше преды- дущего уровня (рис. 1). Такой метод называли "щадящим" и использовали его у больных 2-й группы.

По 2-й методике ИВЛ продолжали в режиме управляемого давления с давлением вдоха, обеспечивающим дыхательный объем (VT), равным VT при предыдущей ИВЛ с управляемым объемом. Увеличивали ПДКВ до 25-30 см вод. ст., при этом давление вдоха повышалось соответственно до 50-60 см вод. ст., а VT снижался (из-за перераздувания некоторых групп альвеол и сдавливания ими других участков легких). Эту методику называли "агрессивной", поскольку при ее применении давление в дыхательных путях увеличивалось значительно больше, чем при "щадящей" мобилизации. В таком режиме ИВЛ проводили в течение 8-10 циклов, осуществляя мониторинг дыхательного объема, ЭКГ, артериального давления и $\mathrm{SpO}_{2}$. Далее пошагово снижали ПДКВ по 3-4 см вод. ст. через каждые 8-10 дыхательных циклов, наблюдая при этом за дыхательным объемом, который начинал увеличиваться - признак открытия дополнительных альвеол (рис. 2).

ПДКВ при максимальном дыхательном объеме считали давлением раскрытия альвеол. Далее определяли уровень ПДКВ, при котором VT начинал снижаться (точка закрытия альвеол). Затем вновь увеличивали ПДКВ и пиковое давление на 15 см вод. ст. выше этой точки закрытия и далее пошагово снижали его до уровня на 2 см вод. ст. выше точки закрытия альвеол, считая его оптимальным на данный момент времени. Некоторым больным приходилось повторять этот прием несколько раз для определе-

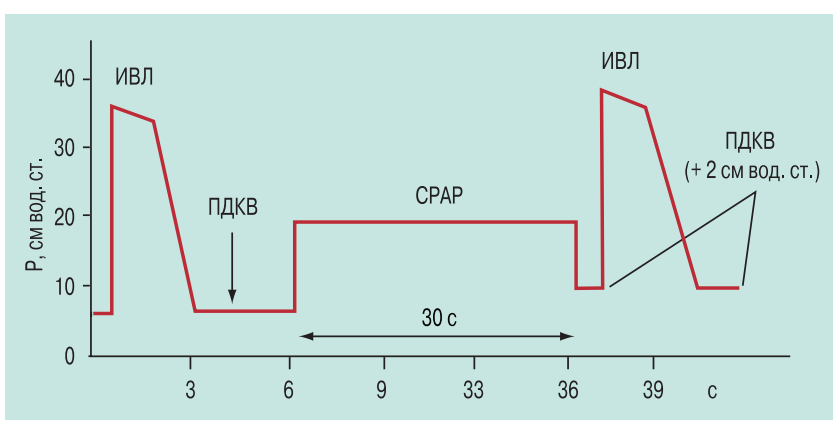

Рис. 1. Мобилизация альвеол по "щадящей" методике

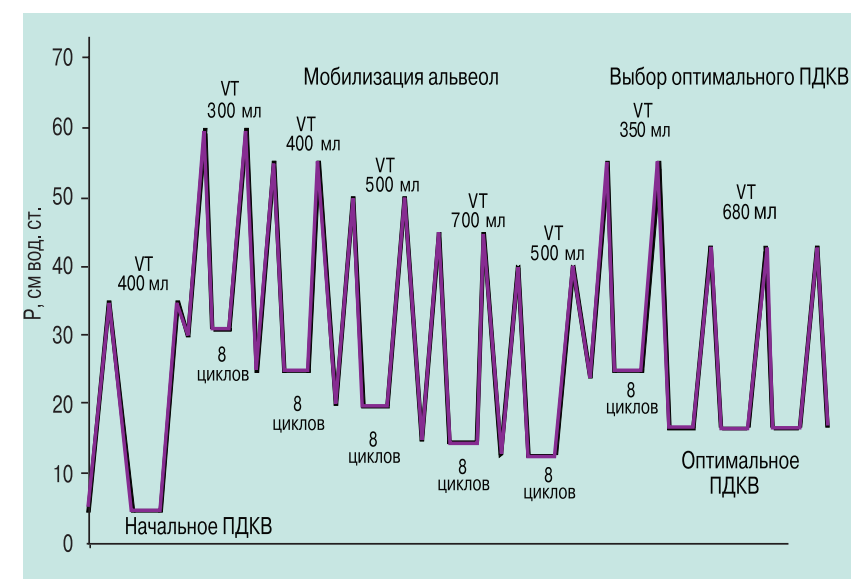

Рис. 2. Мобилизация альвеол по "агрессивной" методике 
ния оптимального уровня ПДКВ. Затем возобновляли ИВЛ в прежнем режиме, который использовали до приема мобилизации, но поддерживали установленное "оптимальное" ПДКВ.

Статистическую обработку полученных данных выполняли при помощи программы Microsoft Excel 2000. Использовались среднее арифметическое $(M)$, его стандартная ошибка $( \pm m)$. Достоверность разницы средних величин оценивали посредством t-критерия Стьюдента. Различия считали достоверными при $p<0,05$.

\section{Результаты и обсуждение}

Как было указано выше, "щадящую" методику мобилизации альвеол применяли у 32 больных 2-й группы, поскольку клинический опыт показал, что для этих пациентов данный прием достаточно эффективен и безопасен. Динамика основных мониторируемых параметров представлена в табл. 3.

Как видно, на пике мобилизации систолическое и диастолическое давление снижалось по сравнению с исходным уровнем, но после окончания процедуры возвращалось к исходному значению. Также на пике достоверно снижалась ЧСС (возможно, в результате воздействия повышенного внутригрудного давления на барорецепторы легких), однако она оставалась в пределах нормальных величин. После окончания приема мобилизации ЧСС увеличивалась, но степень тахикардии становилась достоверно ниже исходной.

$\mathrm{SpO}_{2}$ на пике мобилизации альвеол не изменилась, что можно объяснить кратковременностью и низкой "агрессивностью" самого приема. Намного важнее, что после проведения мобилизации альвеол достаточно быстро - в течение 1 ч - удавалось добиться повышения $\mathrm{SpO}_{2}$ до нормальных цифр и снизить $\mathrm{FiO}_{2}$ до безопасного уровня. Только отдельным больным приходилось повторять расправление альвеол в течение первых суток до 2-3 раз. Все сказанное свидетельствует, что легкие у пациентов 2-й группы не были повреждены в значительной степе-

Таблица 3 Результаты "щадящей"методики мобилизации альвеол

\begin{tabular}{|c|c|c|c|}
\hline Параметры & $\begin{array}{c}\text { До } \\
\text { мобилизации } \\
\text { альвеол }\end{array}$ & $\begin{array}{c}\text { На пике } \\
\text { мобилизации } \\
\text { альвеол }\end{array}$ & $\begin{array}{c}\text { После } \\
\text { мобилизации } \\
\text { альвеол }\end{array}$ \\
\hline $\begin{array}{l}\text { АД систолическое, } \\
\text { мм рт. ст. }\end{array}$ & $150,0 \pm 20,7$ & $107,3 \pm 3,5^{*}$ & $137,9 \pm 2,5^{* *}$ \\
\hline $\begin{array}{l}\text { АД диастолическое, } \\
\text { мм рт. ст. }\end{array}$ & $75,0 \pm 1,8$ & $63,0 \pm 1,9^{*}$ & $75,3 \pm 1,4^{* *}$ \\
\hline ЧСС, мин ${ }^{-1}$ & $98,8 \pm 2,6$ & $64,0 \pm 2,5^{*}$ & $90,0 \pm 1,8^{*}, * *$ \\
\hline $\mathrm{SpO}_{2}, \%$ & $90,5 \pm 0,7$ & $89,6 \pm 1,2$ & $96,0 \pm 0,3^{*, *}$ \\
\hline $\mathrm{FiO}_{2}$ & $0,61 \pm 0,02$ & $0,61 \pm 0,02$ & $0,47 \pm 0,02^{*},{ }^{* *}$ \\
\hline ПДКВ, см вод. ст. & 5 & 20 & 7 \\
\hline $\mathrm{PaO}_{2} / \mathrm{FiO}_{2}$ & $198,7 \pm 17,2$ & & $276,8 \pm 13,78^{*}$ \\
\hline
\end{tabular}

Примечание: * - p < 0,05 по сравнению с периодом до мобилизации; ** - $p<0,05$ по сравнению с периодом на высоте мобилизации.

\section{мобилизации альвеол}

\begin{tabular}{|c|c|c|c|}
\hline Параметры & $\begin{array}{c}\text { До } \\
\text { приема }\end{array}$ & $\begin{array}{l}\text { На высоте } \\
\text { приема }\end{array}$ & $\begin{array}{l}\text { После } \\
\text { приема }\end{array}$ \\
\hline $\mathrm{PaO}_{2} / \mathrm{FiO}_{2}(n=23)$ & $187,57 \pm 11,41$ & & $255,17 \pm 13,62$ \\
\hline $\mathrm{FiO}_{2}(n=23)$ & $0,64 \pm 0,06$ & $0,64 \pm 0,06$ & $0,47 \pm 0,04$ \\
\hline $\mathrm{SpO}_{2}, \%(n=23)$ & $93,2 \pm 0,8$ & $88,7 \pm 0,7^{*}$ & $97,1 \pm 0,5^{*, *}$ \\
\hline VT, мл $(n=23)$ & $435,7 \pm 28,2$ & & $655,5 \pm 22,8^{\star}$ \\
\hline $\begin{array}{l}\text { С легких, } \\
\text { мл / см вод. ст. } \\
(n=23)\end{array}$ & $31,1 \pm 2,8$ & & $48,2 \pm 4,8^{\circ}$ \\
\hline $\begin{array}{l}\text { Транспорт } 0_{2,} \\
\text { мл / мин } / \text { м }^{2} \\
(n=14)\end{array}$ & $638,0 \pm 47,2$ & & $987,0 \pm 47,0^{*}$ \\
\hline $\begin{array}{l}\text { АД систолическое, } \\
\text { мм рт. ст. }(n=23)\end{array}$ & $117,17 \pm 9,04$ & $101,60 \pm 7,46$ & $114,7 \pm 11,5$ \\
\hline ЧСС, мин ${ }^{-1}(n=23)$ & $104,26 \pm 5,46$ & $63,20 \pm 3,48^{*}$ & $94,8 \pm 3,0^{* *}$ \\
\hline $\begin{array}{l}\text { СИ, л / мин } / \text { м² }^{2} \\
(n=14)\end{array}$ & $4,25 \pm 0,25$ & $3,50 \pm 0,42$ & $4,20 \pm 0,22$ \\
\hline $\begin{array}{l}\text { ИГКДО, мл } / \text { м² }^{2} \\
(n=14)\end{array}$ & $777,87 \pm 40,10$ & $624,0 \pm 49,8^{*}$ & $709,93 \pm 51,10$ \\
\hline $\begin{array}{l}\text { ИВГОК, мл } / \text { м² }^{2} \\
(n=14)\end{array}$ & $872,64 \pm 53,16$ & $768,0 \pm 57,9^{*}$ & $863,0 \pm 51,5$ \\
\hline $\begin{array}{l}\text { ИВСВЛ, мл / кг } \\
(n=14)\end{array}$ & $9,80 \pm 0,78$ & $10,00 \pm 1,15$ & $9,10 \pm 0,77$ \\
\hline $\begin{array}{l}\text { ССС, дин } \times с \times \text { см}^{-5} \\
(n=14)\end{array}$ & $774,0 \pm 43,2$ & $957,0 \pm 80,9$ & $831,00 \pm 58,78$ \\
\hline
\end{tabular}

Примечание: * - $p<0,05$ по сравнению с параметрами до мобилизации альвеол; ** - $p<0,05$ по сравнению с параметрами на пике мобилизации альвеол; норма ИГКДО - 640-840 мл / м², норма ИВГОК - 850-1 000 мл / м², норма ИВСВЛ - 3-7 мл / кг, норма ССС - 600-1600 дин Х С X см-5.

ни. Однако успешное завершение мобилизации альвеол указывает на то, что в них имелись зоны нестабильности и микроателектазов, которые удавалось эффективно устранить.

Несмотря на то, что у 9 больных $(28,1 \%)$ гемодинамика была нестабильной и им приходилось проводить постоянную инфузию кардиотоников, приобретенный опыт позволил применять у таких пациентов мобилизацию альвеол в режиме СРАР с достаточно высоким ПДКВ без выраженного и стойкого снижения АД.

У пациентов 2-й группы, по сравнению с 1-й, удалось устранить гипоксемию быстрее, что позволило раньше снизить процент кислорода и в дальнейшем не повышать его, что соответствует принципам безопасной вентиляции. Летальных исходов во 2-й группе не было.

Мобилизацию альвеол в "агрессивном" режиме проводили 23 пациентам 3-й группы. Из них у 9 человек не отслеживали центральную гемодинамику, а у 14 пациентов - контролировали ее при помощи монитора РіССО. Характеристика состояния больных 3-й группы до начала, в процессе процедуры и после нее представлена в табл. 4.

Больные 3-й группы находились в значительно более тяжелом состоянии. Несмотря на использование традиционных методов ИВЛ, повысить индекс оксигенации > 200 у них не удавалось. Это явилось основным показанием к проведению мобилизации 
легких, причем у каждого пациента этой группы приходилось выполнять процедуру неоднократно. Основные мониторируемые параметры представлены в табл. 3 и 4.

В результате приема раскрытия альвеол происходило значительное (на 60 \%) увеличение дыхательного объема, причем в связи с повышением ПДКВ перепад давления в дыхательных путях практически не менялся. Это свидетельствовало об увеличении числа вентилируемых альвеол, что сопровождалось значительным (на 104 \%) повышением динамической растяжимости легких.

Многократное применение приемов раскрытия альвеол позволило подобрать оптимальную величину ПДКВ и повысить $\mathrm{PaO}_{2} / \mathrm{FiO}_{2}$ на 29,9\% $(p<0,05)$, что сопровождалось увеличением $\mathrm{SpO}_{2}$ с субнормальных до нормальных величин. $\mathrm{PaO}_{2}$ поднялось до нормальных значений, что позволило в дальнейшем снизить $\mathrm{FiO}_{2}$. Проведение приемов не прекращали, пока не удавалось уменьшить $\mathrm{FiO}_{2}$ до 0,4 без снижения оксигенации артериальной крови. Показанием к повторной мобилизации альвеол служило снижение $\mathrm{PaO}_{2}$ и $\mathrm{SpO}_{2}$.

Несмотря на применение "агрессивного" приема мобилизации альвеол, у пациентов не снижалось артериальное давление, сердечный выброс или индекс. На пике мобилизации альвеол была отмечена относительная брадикардия, после окончания приема пульс учащался, но тахикардия уменьшалась. При проведении процедуры наблюдалась тенденция к увеличению ССС. После приема происходило достоверное увеличение транспорта кислорода, что свидетельствовало об улучшении оксигенации артериальной крови, а также о том, что прием мобилизации не оказывал значимого отрицательного действия на центральную гемодинамику. Эти результаты согласуются с данными других исследований [15].

На пике мобилизации альвеол достоверно снижались ГКДО и ВГОК, что можно связать с затруднением (снижением) венозного возврата крови, поскольку после окончания приема данные показатели вернулись к прежним значениям. Прием мобилизации не влиял на содержание внесосудистой воды в легких, как можно было ожидать при создании высокого внутригрудного давления. Эти результаты согласуются с данными других исследователей [16]. Несмотря на своевременное и стойкое устранение гипоксемии, летальность в 3-й группе составила $50 \%$, что объясняется тяжестью основных патологических процессов, вызвавших развитие ОДН.

Не были выявлены осложнения приема мобилизации альвеол, например стойкие нарушения гемодинамики или баротравмы легких. После окончания мобилизации у больных продолжали ИВЛ с уровнем ПДКВ, подобранным во время процедуры. Эффект от приема сохранялся обычно на протяжении $\geq 2$ ч, затем $\mathrm{SpO}_{2}$ начинала снижаться, что требовало повторной мобилизации альвеол (5-7 раз в сутки). По мере улучшения состояния пациентов промежутки между приемами удавалось увеличивать до 6-8 ч.

\section{Заключение}

1. Прием мобилизации альвеол значительно улучшает оксигенацию артериальной крови при паренхиматозной дыхательной недостаточности, причем за более короткие сроки, чем этого можно добиться традиционной ИВЛ с высоким содержанием кислорода во вдыхаемом газе.

2. После мобилизации альвеол значительно увеличиваются растяжимость легких и дыхательный объем, что является признаком открытия дополнительного числа вентилируемых альвеол.

3. Мобилизация альвеол не оказывает значимого и стойкого отрицательного действия на гемодинамику, а "щадящий" вариант может быть рекомендован для улучшения оксигенации артериальной крови при множественных позиционных ателектазах.

\section{Литература}

1. Адроге Г.Дж., Тобин М.Дж. Дыхательная недостаточность: Пер. с англ. М.: Медицина; 2003.

2. Чучалин А.Г. Тяжелая астма: актуальная проблема медицины. Лекция на IX конгрессе Европейского респираторного общества. Мадрид; 1999.

3. Кассиль В.Л. Острый внелегочный респираторный дистресс-синдром: определение, этиопатогенез, клинические и лабораторные проявления. Онкогематология 2011; 1: 54-66.

4. Кассиль В.Л., Выжигина М.А., Хапий Х.Х. Механическая вентиляция легких в анестезиологии и интенсивной терапии. М.: Медицина; 2009.

5. Lachman B. Open up the lung and keep the lung open. Int. Care Med. 1992; 18 (3): 319-321.

6. Марченко Ю.В., Измайлов В.В., Козлова Е.М., Богомолов П.В. Эффективность "открытия альвеол" у больных с острым повреждением легких и сопутствующим пневмотораксом. Общая реаниматол. 2009; 5 (2): 17-20.

7. Brower R.G., Morris A., MacIntyre N. et al. Effects of recruitment maneuver in patient with acute lung injury acute respiratory distress syndrome ventilated with high end expiratory pressure. Crit. Care Med. 2003; 31 (11): 2592-2597.

8. Constantin J.M., Futier E, Cherprenet A.L. et al. A recruitment maneuver increases oxygenation after intubation of hypoxemic intensive care unit patients: a randomized controlled study. Crit. Care 2010; 14 (2): R76.

9. Caironi P., Cressoni M., Chiumello D. et al. Lung opening and closing during ventilation of acute respiratory distress syndrome. Am. J. Respir. Crit. Care Med. 2010; 181 (6): 578-586.

10. Gattinoni L., Carlesso E., Brazzi L., Caironi P. Positive endexpiratory pressure. Curr. Opin. Crit. Care 2010; 16 (1): 39-44.

11. Choi H.S., Hong S.B., Lim C.M. et al. Efficacy of positive end-expiratory pressure titration after the alveolar recruitment manoeuvre in patients with acute respiratory distress syndrome. Crit. Care 2009; 13 (1): R 22.

12. Rocco P.R., Pelosi P., de Abreu M.G. Pros and cons of recruitment maneuvers in acute lung injury and acute respiratory distress syndrome. Exp. Rev. Respir. Med. 2010; 4 (4): 479-489.

13. Grasso S., Stripoli T., Sacchi M. et al. Inhomogeneity of lung parenchyma during the open lung strategy: a computed 
tomography scan study. Am. J. Respir. Crit. Care Med. 2009; 180 (5): 415-423.

14. Huh J.W., Jung H., Chacko J. et al. Alveolar recruitment maneuvers in acute lung injury / acute respiratory distress syndrome. Indian J. Crit. Care Med. 2009; 13 (1): 1-6.

15. Huh J.W., Hong S.B., Lim C.M. et al. Effect of the alveolar recruitment manoeuvre on haemodynamic parameters in patients with acute respiratory distress syndrome: relationship with oxygenation. Respirology 2010; 15 (8): $1220-1225$.

16. Toth I., Leiner T., Mikor A. et al. Hemodynamic and respiratory changes during lung recruitment and descending optimal positive end-expiratory pressure titration in patients with acute respiratory distress syndrome. Crit. Care Med. 2007; 35 (3): 787-793.

\section{Информация об авторах}

Сапичева Юлия Юрьевна - врач анестезиолог-реаниматолог отделения реанимации и интенсивной терапии МОНИКИ им. М.Ф.Владими рского; тел.: 8-916-248-44-92; e-mail: sapchikjul@mail.ru

Кассиль Владимир Львович - д. м. Н., проф., и. о. зав. отделения госпитальной терапии и функциональной диагностики НИИ клинической онкологии Российского онкологического научного центра им. Н.Н.Блохина РАМН; тел.: 8-903-157-06-48; e-mail: vkassil@bk.ru

Хапий Ирина Халидовна - к. М. н., доцент кафедры анестезиологии и реаниматологии ФУВ МОНИКИ им. М.Ф.Владимирского; тел.: 8-910441-54-41; e-mail: aro xxx@monikiweb.ru

Поступила 04.10.11

(с) Коллектив авторов, 2011 удК 616.24-008.44-092 